\title{
Motor racing accidents at Brands Hatch, 1988/9
}

\author{
M. A. S. Chapman MA, MB BS and J. Oni* MA, FRCS \\ The Royal London Hospital, London and *Queen Mary's Hospital, Sidcup, Kent, UK
}

\begin{abstract}
Little is known about the incidence of injury to race track motor-cyclists and car drivers. In a 1-year study at Brands Hatch, 70 of 33184 competitors required hospital treatment. We found this injury rate to be higher than on the public highway. However, the anatomical distribution of injury caused by motor-bike accidents is similar to that found on the public highway. Motor-cyclists are more likely than car drivers to sustain limb trauma requiring outpatient treatment only. The number of participants requiring admission to hospital is broadly similar for car and bike races, being less than $0.1 \%$.
\end{abstract}

Keywords: Car, motor-bike racing, injuries, Brands Hatch

Motor-bike and car racing are considered to be glamorous high-risk sports with many thrills and spills, possibly encouraged by live television coverage and the repeated showing of spectacular accidents. We reviewed retrospectively the injuries sustained at Brands Hatch, one of only two Grand Prix circuits in the UK used by participants in motor-car and bike racing. We hoped to assess the degree of risk, the nature of injuries sustained and the extra workload generated for the local district general hospital.

\section{Method}

Brands Hatch is an international race circuit and is therefore subject to the high safety standards maintained by the governing bodies, FISA, FIA ${ }^{1}$, FIM $^{2}$, and thus high standards are achieved. Much work has been done on improving race-track safety, vehicle design, and the rapid extraction and evacuation of patients to hospital, as well as the immediate resuscitation of the trapped victim ${ }^{3-6}$. At Brands Hatch the on-site medical officers are responsible for triage and, if appropriate, treat patients, including spectators and mechanics. Those with more than the most trivial of complaints are sent to Queen Mary's Hospital, Sidcup, a 10-min ambulance journey away.

Address for correspondence: Dr M.A.S. Chapman, The Surgical Unit, Alexandra Wing, Royal London Hospital, London E1, UK

(C) 1991 Butterworth-Heinemann Ltd.

0306-3674/91/030121-03

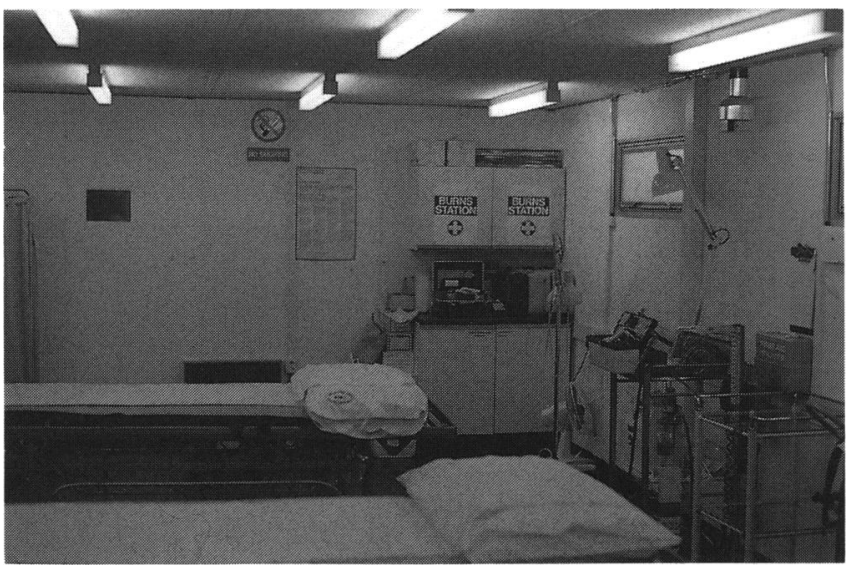

A log book at Brands Hatch, in which all attendances are recorded, was used to provide preliminary details of each patient, further information being obtained from hospital notes, casualty cards or a telephone call to individual racers when records were incomplete. The results were analysed according to the anatomical site of injury; if the patient had injuries to different parts of the body, i.e. a fractured arm and leg, these were counted separately. Whether the patient was admitted overnight or not provided a rough assessment as to the severity of the injury.

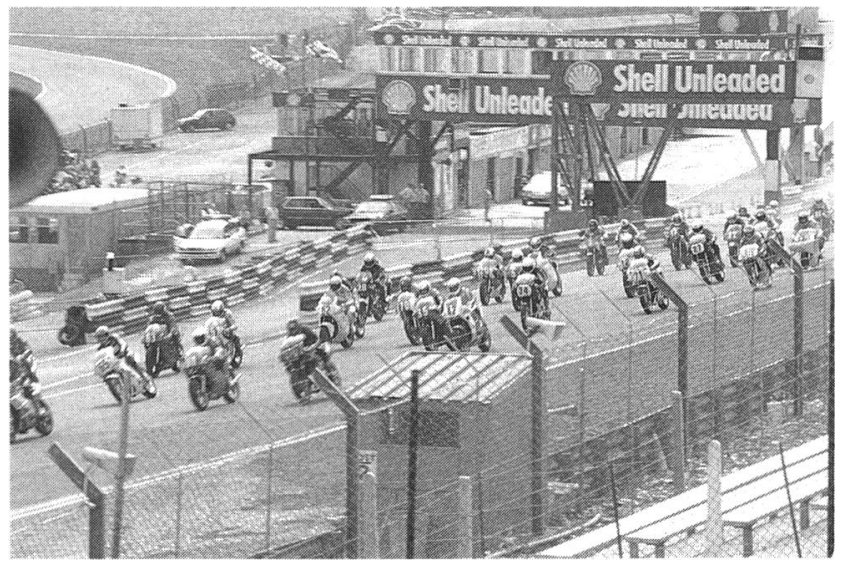




\section{Results}

From August 1988 to August 1989, 70 racers were advised to attend hospital and a total of 89 injuries recorded.

During the period of study there were 29 days of motor-bike racing with 19 solo races and two sidecar races a day. In the solo races there were between 36 and 40 riders; in the sidecar races 30 to 48 vehicles. Consequently, in excess of 23000 riders started a race, of whom 56 required hospital treatment: 19 required admission and there were three deaths, all dead on arrival at hospital, two from severe head injuries and the other one from chest injuries. Thus only $0.24 \%$ of bike riders starting a race required hospital treatment.

This incidence compares favourably with the results of a 2-year study at Mondelo motor-cycle track where the incidence was $1.4 \%$ of 4050 riders ${ }^{7}$.

At Brands Hatch there were 52 days of motor-car racing with four single-seater and six saloon races a day, each involving between 28 and 30 single-seater and 30 to 34 saloon cars in each race. Thus a total of 9984 competitors started a car race, 14 of whom required hospital treatment. There were no deaths and five people required admission. Thus $0.14 \%$ of car racers starting a race had a crash requiring hospital treatment.

\section{Discussion}

The results show that, of motor-cycle injuries not requiring hospital admission, 40 occurred among 37 riders, 31 of these injuries affected the limbs (Table 1). Of the injuries requiring admission, there were more multiple injuries, 29 affecting 19 riders. There was a roughly equal distribution of injury to the limbs,

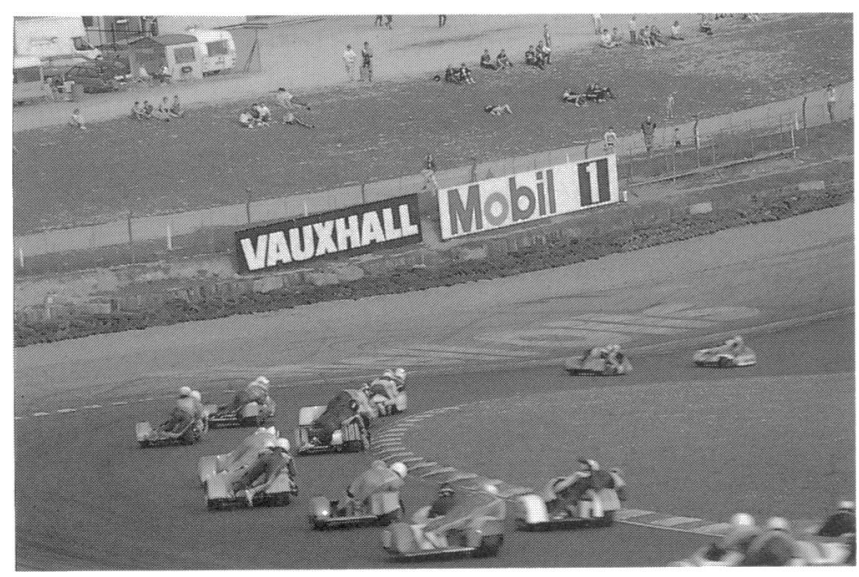

Table 1. Number of injuries occurring in motor-bike races, by anatomical site and whether overnight admission was required

\begin{tabular}{|c|c|c|c|c|c|}
\hline & \multirow{2}{*}{$\begin{array}{l}\text { Head } \\
\text { and } \\
\text { neck }\end{array}$} & \multirow{2}{*}{$\begin{array}{c}\text { Thorax } \\
\text { and } \\
\text { abdomen }\end{array}$} & \multicolumn{2}{|c|}{ Limbs } & \multirow{2}{*}{$\begin{array}{c}\text { Injuries/ } \\
\text { people }\end{array}$} \\
\hline & & & Upper & Lower & \\
\hline $\begin{array}{l}\text { Discharged } \\
\text { Admitted }\end{array}$ & $\begin{array}{l}3 \\
8\end{array}$ & $\begin{array}{l}6 \\
6\end{array}$ & $\begin{array}{r}20 \\
9\end{array}$ & $\begin{array}{r}11 \\
6\end{array}$ & $\begin{array}{l}40 / 37 \\
29 / 19\end{array}$ \\
\hline
\end{tabular}

trunk, and head and neck. The anatomical distribution of motor-cycle injuries occurring on a race track was similar to that reported by Andrew ${ }^{8}$ who reviewed the casualties from motor-cycle accidents attending Newcastle General Hospital over a 6month period (Table 2). However, these casualties were not triaged by a medical officer at the site of accident (unlike those at Brands Hatch) and this might account for the higher admission rate for the Brands Hatch group.

Among the car drivers 18 of 20 injuries affected the head, neck and legs (Table 3). Similarly, with bike racing, hospital admission was more likely if more than one injury was sustained.

During the year of study about $366715 \mathrm{~km}$ were completed by motor-bike riders and $479028 \mathrm{~km}$ by car drivers. Thus, per 100 million kilometres the injury rate is about 15270 and 2922 injuries respectively compared with 789 and 58 accidents per 100 million kilometres on the public highway ${ }^{9}$.

At present there are no data available about the number of accidents that occur at Brands Hatch; however, it is interesting that in the period between March and October 1988, Kent Racing Combine (KRC) reported 414 fallers from motor-bikes, an average of about 30 a day. Thus most motor-bike accidents do not result in significant injury; this is an area for further research.

\section{Conclusion}

This is the first study to analyse the incidence of injury at a major race track in the UK. The likelihood of sustaining an injury at Brands Hatch is greater than on the public highway.

Motor-bike racing produces many more minor fractures to the limbs than car racing. However, this difference narrows when the more serious injuries

Table 2. Comparison of incidence of anatomical site of a motor-bike injury on the public road with that on the race track

\begin{tabular}{lllllr}
\hline & $\begin{array}{c}\text { Brands Hatch } \\
\text { (motor-bikes } \\
\text { only) }\end{array}$ & & \multicolumn{2}{c}{$\begin{array}{c}\text { Motor-bike } \\
\text { road accidents } \\
\text { (from Andrews) }\end{array}$} \\
\cline { 2 - 3 } \cline { 5 - 6 } Anatomical region injured & No. & $\%$ & & No. & $\%$ \\
\hline Head and neck & 11 & 16 & 9 & 11 \\
$\begin{array}{l}\text { Thorax and abdomen } \\
\text { Upper limb }\end{array}$ & 12 & 17 & 10 & 12 \\
$\begin{array}{l}\text { Lower limb } \\
\text { Overnight admission rate }\end{array}$ & 29 & 42 & 35 & 42 \\
\hline & 17 & 25 & 29 & 35 \\
\hline
\end{tabular}

Table 3. Number of injuries occurring in car races, by anatomical site and whether overnight admission was required

\begin{tabular}{|c|c|c|c|c|c|}
\hline & \multirow{2}{*}{$\begin{array}{l}\text { Head } \\
\text { and } \\
\text { neck }\end{array}$} & \multirow{2}{*}{$\begin{array}{c}\text { Thorax } \\
\text { and } \\
\text { abdomen }\end{array}$} & \multicolumn{2}{|c|}{ Limbs } & \multirow{2}{*}{$\begin{array}{c}\text { Injuries/ } \\
\text { people }\end{array}$} \\
\hline & & & Upper & Lower & \\
\hline Discharged & 7 & 1 & 0 & 4 & $12 / 9$ \\
\hline Admitted & 2 & 0 & 1 & 5 & $8 / 5$ \\
\hline
\end{tabular}




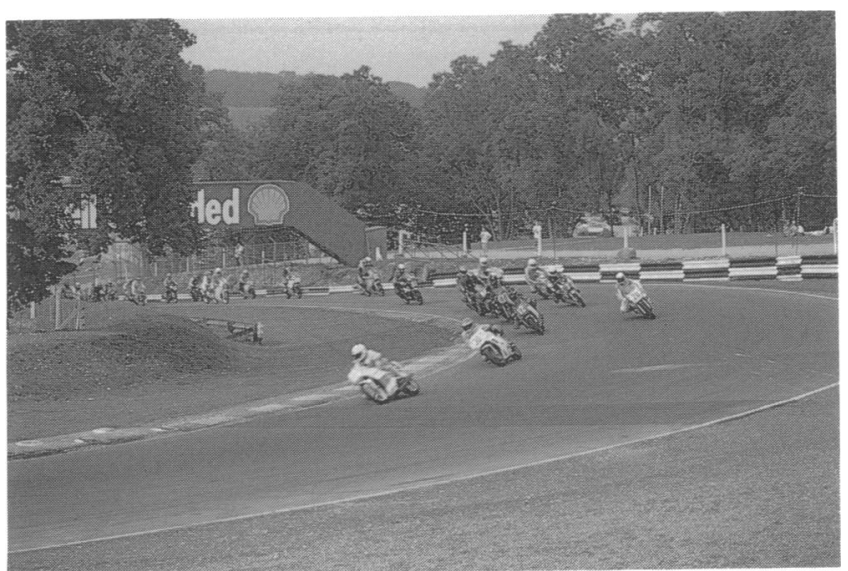

Table 4. Percentage chance of significant injury in a race. Sample population 33000 competitors

\begin{tabular}{lcc} 
& Hospital treatment (\%) & Hospital admission (\%) \\
\hline Motor-bike & 0.24 & 0.08 \\
Car & 0.14 & 0.05 \\
\hline
\end{tabular}

are considered, the admission rate being surprisingly similar (Table 4).

Bike-riders at Brands Hatch sustained a high proportion of minor limb injuries. Thus a limb injury must be sought in all bike-riders who crash, particularly when a serious head, neck, chest or abdominal injury has occurred. The similar distribution of injuries sustained on the public highway and the motor racing circuit is interesting, as road accidents implicate a variety of vehicle types, roadside furniture and night travel which are all absent on the race track (Figure 1). This similarity emphasizes the relevance of motor racing to the design and safety of road vehicles.

The majority of injuries sustained by car drivers affect the head and neck, or the legs which are easily trapped by a buckled dashboard; in a single-seater car, despite special strengthening of the dashboard, it is prone to being crushed round the drivers' ankles.

In the year of study the workload of Queen Mary's Hospital, Sidcup, was increased by about one patient every 5 days.

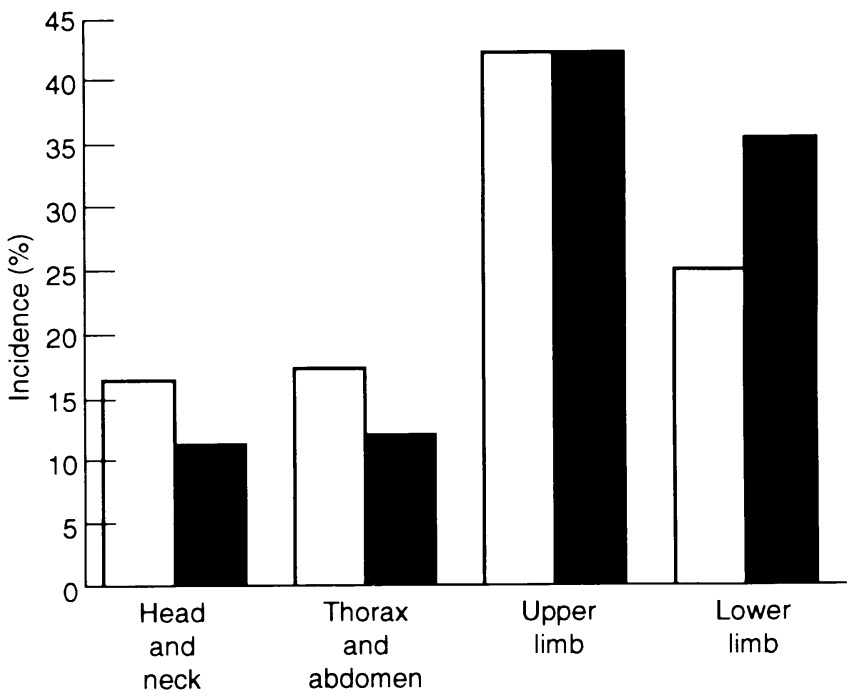

Figure 1. Anatomical location of injury to motor-cyclists: comparison of the incidence on the race track and the public road. $\square$, Race track; $\boldsymbol{\square}$, public road

\section{Acknowledgements}

We wish to thank the personnel at Brands Hatch, especially Mr D. Miller, and Messrs M. Rowntree and A. Percy for allowing us to report on their patients

\section{References}

Federation Internationale de l'Automobile Year (Yellow) Book.

2 Federation Internationale du Motorcycle Year Book.

3 Crippen D, Olvey S, Edwards S. Acute medical care for championship auto racing. Ann Emerg Med 1985; 14: 249-53.

4 Olvey S. Autoracing, is there a lesson to be learnt? Indiana Med 1987; 80: 462-4.

5 Snook R. Medical aid at accidents. Update 1974; 8: 215-36.

6 Nancekievill D. Rescue and treatment of the injured motor racing driver. Br J Hosp Med 1972; 7: 593-600.

7 Horner $\mathrm{C}, \mathrm{O}^{\prime}$ Brien $\mathrm{A}$. Motorcycle racing injuries on track and road circuits in Ireland. $\mathrm{Br}$ I Sports Med 1986; 20: 157-8.

8 Andrews T. A six month review of motorcycle accidents. Injury 1979; 10: $317-20$

9 Department of Transport. Road Accidents GB 1988: The Casualty Report. London: HMSO, 20-1. 